\title{
Socio-hydrologic perspectives of the co-evolution of humans and water in the Tarim River basin, Western China: the Taiji-Tire model
}

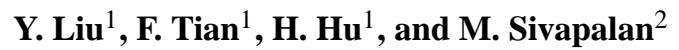 \\ ${ }^{1}$ State Key Laboratory of Hydroscience and Engineering, Department of Hydraulic Engineering, Tsinghua University, \\ Beijing 100084, China \\ ${ }^{2}$ Department of Civil and Environmental Engineering, Department of Geography and Geographic Information Science, \\ University of Illinois at Urbana-Champaign, Urbana, IL 61801, USA
}

Correspondence to: F. Tian (tianfq@ @tsinghua.edu.cn)

Received: 22 September 2013 - Published in Hydrol. Earth Syst. Sci. Discuss.: 28 October 2013

Revised: 17 February 2014 - Accepted: 25 February 2014 - Published: 3 April 2014

\begin{abstract}
This paper presents a historical socio-hydrological analysis of the Tarim River basin (TRB), Xinjiang Uyghur Autonomous Region, in Western China, from the time of the opening of the Silk Road to the present. The analysis is aimed at exploring the historical co-evolution of coupled human-water systems and at identifying common patterns or organizing principles underpinning socio-hydrological systems (SHS). As a self-organized entity, the evolution of the human-water system in the Tarim Basin reached stable states for long periods of time, but then was punctuated by sudden shifts due to internal or external disturbances. In this study, we discuss three stable periods (i.e., natural, human exploitation, and degradation and recovery) and the transitions in between during the past 2000 years. During the "natural" stage that existed pre-18th century, with small-scale human society and sound environment, evolution of the SHS was mainly driven by natural environmental changes such as river channel migration and climate change. During the human exploitation stage, especially in the 19th and 20th centuries, it experienced rapid population growth, massive land reclamation and fast socio-economic development, and humans became the principal players of system evolution. By the 1970s, the Tarim Basin had evolved into a new regime with a vulnerable eco-hydrological system seemingly populated beyond its carrying capacity, and a human society that began to suffer from serious water shortages, land salinization and desertification. With intensified deterioration of river health and increased recognition of unsustainability of traditional development patterns, human intervention and recovery measures have since been adopted. As a result, the basin
\end{abstract}

has shown a reverse regime shift towards some healing of the environmental damage. Based on our analysis within TRB and a common theory of social development, four general types of SHSs are defined according to their characteristic spatio-temporal variations of historical co-evolution, including primitive agricultural, traditional agricultural, industrial agricultural, and urban SHSs. These co-evolutionary changes have been explained in the paper in terms of the Taiji-Tire model, a refinement of a special concept in Chinese philosophy, relating to the co-evolution of a system because of interactions among its components.

\section{Introduction}

Water is the basis of all life, a key factor in production of commodities important to human well-being, and is essential for the maintenance of ecosystem health. Many of the great ancient civilizations such as Egypt, China, India and Babylon, have developed along famous rivers, such as the Nile, Yellow, Ganges, Euphrates and Tigris, respectively. In the long history of human civilization, people first gathered along river banks, and then gradually expanded away from rivers as they established tribes, villages and cities, accompanied by increasing complexity of social structures. During this evolutionary process, natural water conditions posed important constraints on human activities and thus the evolution of society, and in return human activities, impacted natural water regimes significantly as well (Ponting, 1992). Recently as well as in the historic past, improper or excessive 
utilization of water resources and the consequent waterrelated problems (e.g., salinization, pollution, flooding, water scarcity etc.) have hampered sustainable development of human societies (Brink et al., 1990; Ibe and Njemanze, 1999; Klocking et al., 2003; Gordon et al., 2008; Schilling et al., 2008; Ferreira and Ghimire, 2012; Li et al., 2012). In fact, as pointed out by Costanza et al. (2007), human responses to both environmental stress and social change in turn feed climate and ecological systems, which produces a complex web of multi-directional inter-connections in time and space. Understanding such human-water relationships and their evolutionary dynamics is of great importance for sustainable development of human societies, which is the aim of the newly emergent discipline of socio-hydrology (Sivapalan et al., 2012).

Historical analysis serves as one of the key methodologies of socio-hydrological study (Sivapalan et al., 2012). Basically, this involves studying the past (i.e., immediate past or even distant past) and reconstructing the associated coevolutionary socio-hydrologic processes, through systematic analysis of the social and physical events and mechanisms and their interactions that together may have contributed to such history, and organizing them into distinct phases. Although accurate historical data are not always available and the co-evolution processes often tend to be ambiguous, the historical patterns of human-environment interactions may still be reconstructed with the support of the relevant "grey" literature and other archeological findings (Costanza et al., 2007; Ponting, 1992).

This paper represents a first attempt at undertaking such a historical socio-hydrological study of the Tarim River basin (TRB), located in Western China, from the distant past (more than two millennia before present) to the present. With a current population of over 10 million and a long and varied history of human settlement, the Tarim River basin presents itself as a study area where the interactions and feedbacks between human and water systems are very pronounced, the understanding of which will be useful for addressing even contemporary water sustainability challenges. In this inland basin, the climate is hyper-arid and the river runoff is principally formed from the thawing of glaciers and mountain snow, as well as orographically generated rainfall in the Mt. Kunlun and Tianshan surrounding it. In the geological past, the main course of the Tarim River has experienced frequent shifts, which helped to shape a highly mobile and star-studded pattern of oases (i.e., the oases were not linked but were isolated from each other). In terms of human history, the basin gave birth to a special type of scattered city-state civilization and eventually became the meeting point between the Eastern and Western worlds with the establishment of the Silk Road in 138 B.C. The region has a rich written history of over 2000 years, with the development of human society and socio-economic formation that encompass transitions from the primitive stage to traditional agriculture, then modern agriculture, and finally to the industrial stage that prevails at present. The TRB sociohydrological system displays distinct features in each of its development stages. Along the way, the human-water relationship also evolved from a nature-dominated regime to a human-dominated regime with the growth of social productive forces (most notably technology). The social productive force is a core concept in Marxist philosophy, which is used to describe the ability of human societies to exploit resources (both natural and social) to meet societal needs. More details could be found in a Wikipedia entry under productive forces: http://en.wikipedia.org/wiki/Productive_forces.

Although there have been several studies that focused on more recent decades of the human-water relationship within the TRB (Chen et al., 2005; Hao et al., 2009; Pang et al., 2012; Zhou et al., 2012), the much longer-term dynamics of coupled social, hydrological as well as the associated climatic and ecological changes have not been comprehensively analyzed. What is more, there is a considerable lack of an overview of such human-water history, which will be the focus of this paper. The historical analysis of the co-evolution of the socio-hydrological system within TRB could not only improve our understanding of past human-water relationships but also facilitate improved predictions of its possible future dynamics. Also, it has the potential to generate information and insights that will be valuable for comparative socio-hydrologic studies across different human-water systems around the world and could provide insights that might guide more detailed quantitative process studies and modeling in specific places.

The remainder of the paper is organized as follows. Section 2 provides an introduction to the study area, including a historical overview of the co-evolution of humans and water within the TRB. In Sect. 3, a general framework called the Taiji-Tire model is proposed for analyzing and interpreting the interactions between humans and water within the TRB, and more generally, also provides a foundation for the detailed discussion that will follow. The following three sections describe the salient features of, and the mechanisms behind, the co-evolution of the TRB socio-hydrological system over three distinct stages of development (i.e., natural, exploitation and recovery stages). The paper then concludes with a summary of the results and conclusions, a classification of the SHSs and some perspectives on possible future research.

\section{Study area}

The Tarim River basin is located within the Xinjiang Uyghur Autonomous Region, northwestern China (see Fig. 1 for its landscape and Fig. 2 for the location and the river system). It is surrounded by Mt. Tianshan in the north and Mt. Kunlun in the south. This great basin with an area of $1100000 \mathrm{~km}^{2}$ derives its name from the Tarim River, which flows through Taklimakan, China's largest desert. The word "tarim" is used 

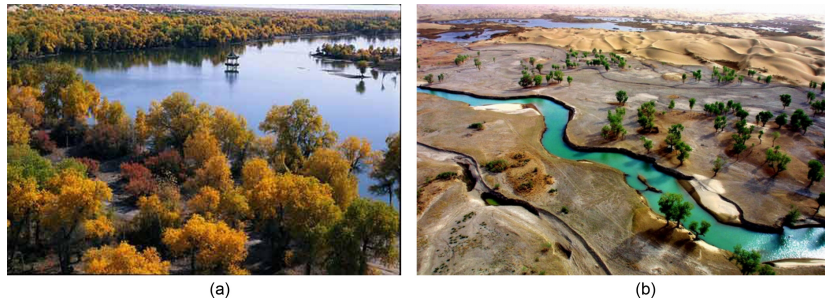

Fig. 1. The landscape of (a) main stream of Tarim River (adapted from http://travel.sina.com.cn/china/2009-03-16/165869875. shtml) and (b) the lower reaches of the Tarim River (adapted from http://my.opera.com/frampa62/albums/showpic.dml?album= $12297572 \backslash \&$ picture $=160178642$ ).

to designate the banks of a river that is not able to be differentiated from the sands of a desert (see Wikipedia website, http: //en.wikipedia.org/wiki/Tarim_River). Nowadays, the TRB has a hyper-arid climate with average annual precipitation of just 50-100 mm (and almost zero in the Taklimakan Desert and the Lop Nor Basin). The streamflow in the river mainly comes from the surrounding mountains. The maximum temperature in the TRB is about $40^{\circ}$.

The Tarim River has four tributaries, namely the Aksu River, Yarkand River, Hotan River, and Kongqi River. The name Tarim is applied to the river formed by the union of the Aksu River, Yarkand River, and Hotan River, near Aral City in western Xinjiang, which is deemed as the mainstream of the Tarim River. The mainstream is divided into 3 parts: the upstream part from Aral to Yenbazar, the middle part from Yenbazar to Karal, and the downstream part from Karal to its terminal lake. The Tarim River empties into its terminal lake (Taitema Lake) intermittently after flowing $1312 \mathrm{~km}$ from Aral. Historically, the terminus of the Tarim River system was Lop Nor Lake, which is about $160 \mathrm{~km}$ northeast of the present Taitema Lake.

Historically, during the past 2000 years, the climate of TRB experienced significant variations, which can be roughly divided into several phases: warm-wet, warm-dry, cool-wet, cool-dry, ice age, and several intermission periods (Sun et al., 2005). The variations of temperature and precipitation have strong influences on the melting processes and ice-snow storage in Mt. Tianshan and Mt. Kunlun. The resulting variation of runoff, together with the impact of channel sediment deposition and the drifting of the desert, caused overflowing and twisting processes, which led to frequent river course migrations, as well as associated degradation and regeneration of oases that humans and plants relied on (Fan and Cheng, 1981; Wang et al., 1996; Shu et al., 2003; Wei, 2008; Xie, 2008).

The history of human activities within TRB goes all the way back to the Stone Age. Since at least 2000 BC, primitive tribes have settled in this region despite tough environmental conditions and the enormous distances separating them from ancient civilization centers, such as China, Egypt, and the

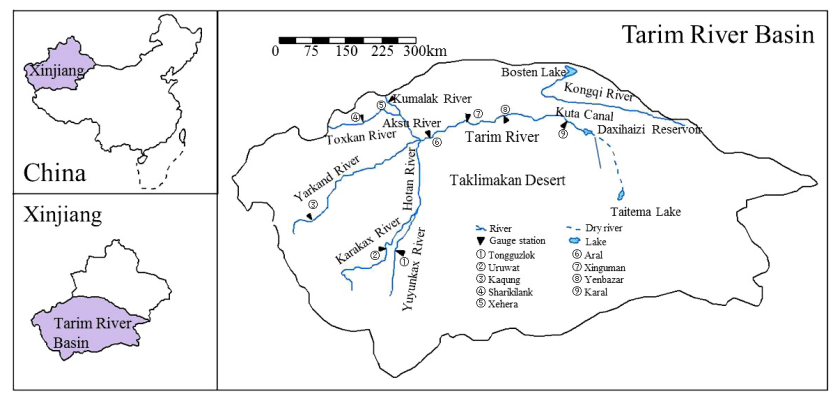

Fig. 2. Overview of Tarim River basin and its river system (adapted from Hao et al., 2009).

Fertile Crescent (Wang, 1983; Shu et al., 2003). City-states appeared in oases along the river with populations in the hundreds to a few thousand only (Han, 2010). The spatial variability of climatic and eco-hydrologic conditions within the TRB led to diverse development paths and socio-economic formations. In the northern edge of the TRB, influenced by nomadic civilizations further up north, fishing and grazing modes of production lasted for quite a long time. Until the late 18th century, there still lived inhabitants called Lopliks in the Lop Nor region who relied on primitive fishing and grazing and could not even digest grains (Han and Lu, 2006). In contrast, irrigation agriculture appeared much earlier along the southern edge and in the source areas of the TRB, especially in the sub-basins of Aksu, Hotan, Niya and Keriya and the ancient Qiemo river (Sun et al., 2005). These are the earliest places that received a massive migration of people and the introduction of advanced agricultural tools and technologies from Chinese agricultural civilizations in the east (Liao, 2011).

The socio-economic formation within the TRB passed through several different stages - from primitive society (fishing, hunting, gathering), agricultural society (grazing, farming), and on to the industrial society that prevails now. Furthermore, the agricultural societies that existed can be divided into those operated in the traditional agricultural mode and those in a modern agricultural mode. In the traditional mode, agricultural production was primarily driven by human and animal power, and in the modern mode, production was driven by machine power that emerged following the industrial revolution. Roughly speaking, traditional agriculture society within the TRB reached its peak in the 19th to the 20th centuries, and modern agriculture started in the 1950s (Tong, 2006).

Roughly consistent with the evolution of these socioeconomic formations, the TRB experienced a paradigm shift in its human-water relationships as well (Table 1). For example, in the primitive period, the human impact on the hydro-ecological system was limited to simple water extraction for domestic use and other limited agricultural activities. As the human system developed, the SHS also evolved and at some local scales humans became more important. 
Table 1. Spatial features and the ages of four types of socio-hydrological systems (SHSs): the ages of the four types of SHS do not strictly match the human development stages because the latter are divided on the basis of human-water relationships and dominant factors underpinning the human-water interactions, whereas the types of SHSs are classified mainly on the basis of socio-economic formations.

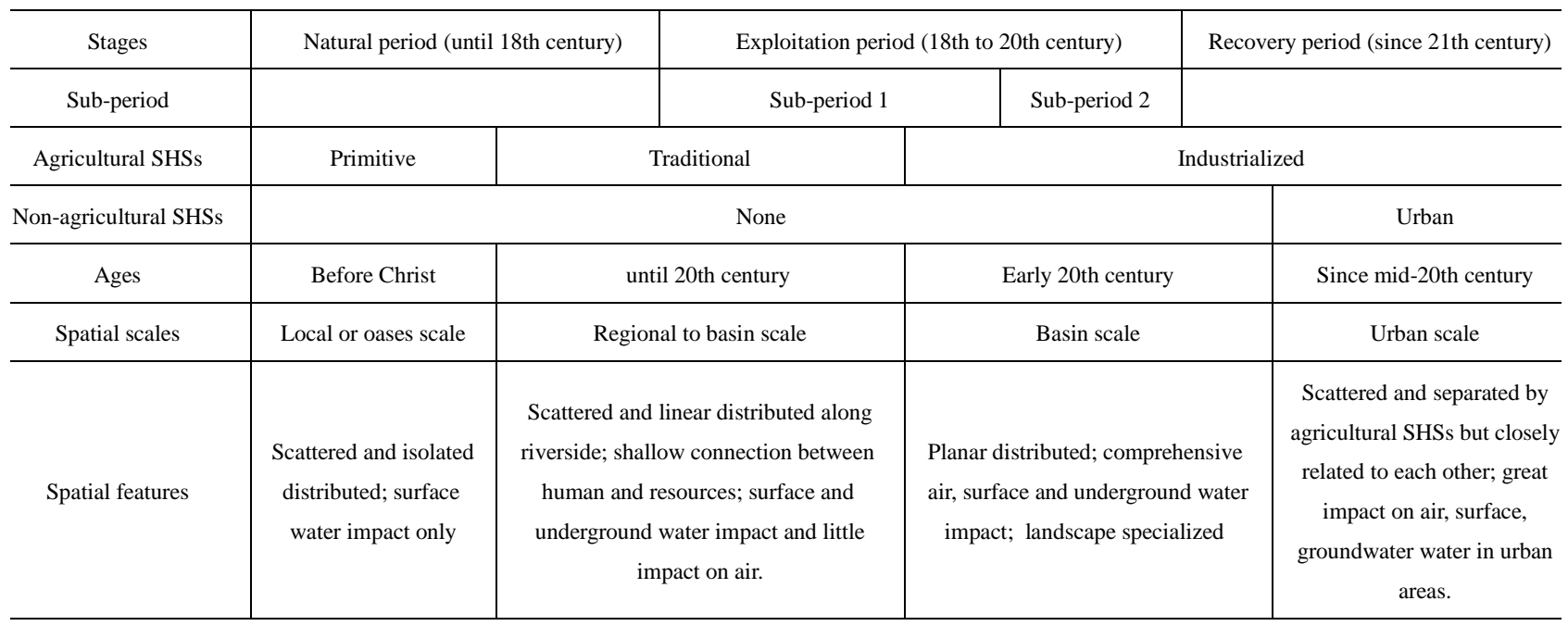

In the era of the modern agricultural society, as the social productive force was significantly upgraded, large-scale agricultural infrastructure (e.g., diversion canals, reservoirs, and groundwater wells) were constructed and human factors and innovation gradually became the dominant drivers. Specifically, since the 1970s the downstream area of the Tarim River has suffered from serious water shortages caused by overexploitation in upstream source areas. Water shortage and soil salinization enhanced ecological degradation and desertification (Chen et al., 2006; Tong et al., 2006), which in turn seriously restricted socio-economic development. Human society responded to the resulting more intensive human-water relationship by undertaking large engineering projects (e.g., emergence of large water transfers since 2000) as well as management measures (e.g., setting up of the Tarim River Basin Authority in 1992), which helped to restore the ecological system to some extent (Sun et al., 2004; Chen et al., 2007a, b).

Therefore, in terms of the human-water relationships, in this paper we divide the co-evolutionary history of the SHS within TRB into three stages: the natural stage from around the 2 nd century BC to the 18 th century AD which is dominated by natural factors, the exploitation stage from the 18 th century to mid-20th century when humans gradually become the dominating factors and the degradation and recovery stage from the mid-20th century up until human-dominated mechanism evolved. A detailed discussion of each stage will be presented in Sects. 4 to 6 using the Taiji-Tire model, a comprehensive organizing framework that is presented next.

\section{Taiji-Tire model: a general framework for analyzing the interactions between humans and water}

Careful analysis of the co-evolutionary history of the coupled human-water system within TRB suggested that the system evolution is essentially driven by two classes of factors (i.e., the natural and the social) and that the essence of the human-water relationship is associated with water consumption at different spatio-temporal scales. The natural and social drivers of human-water system co-evolution are functioning to either reinforce or weaken the degree and scales of water consumption.

Water consumption is regarded as direct human-water interaction, with all the natural and societal factors (e.g., climate, geology, societal regimes and policies) influencing the supply and demand of water resources being considered as outer environmental conditions. The direct water consumption and the relevant factors together reflect the nature of human-water relationship. In order to better understand the co-evolution process of a socio-hydrological system, we propose an organizing framework called the Taiji-Tire model to represent and explain the human-water relationship within the TRB.

The SHS within TRB can be seen as an intertwined system consisting of the human, hydrological and environmental sub-systems. As illustrated in Fig. 3a, the inner solid circle is a specific social-hydrological system under study (in this case the TRB), and the outer dashed circle is its environmental system composed of both humans and nature. Within the inner circle, the water and human parts interact via their water-centered eco-environment (water is the key factor in the eco-environment) in a complex way, which may be represented by relationships that may eventually be quantified 


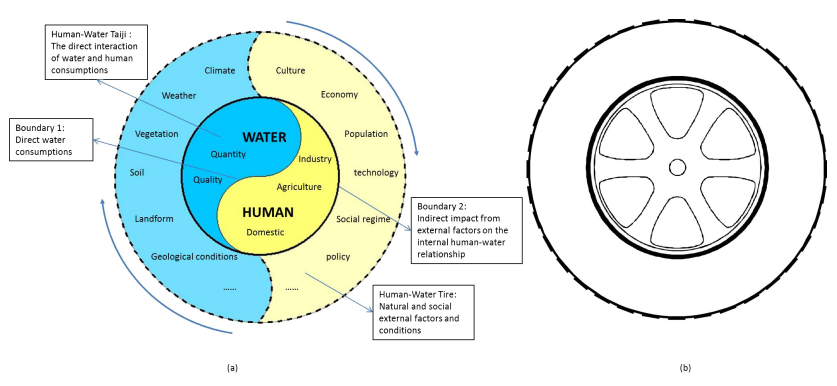

Fig. 3. The Taiji-Tire model applied for historical sociohydrological analysis in TRB: (a) the Taiji-Tire model; (b) the Tire symbol. The human-water Taiji represents the core of the humanwater relationship for a specific SHS. The human-water tire contains the external natural and social conditions. Two boundaries are illustrated and represent two kinds of relations: (i) the direct human-water interaction as water consumption in the inner Taiji, which is the internal human-water relationship, and (ii) the indirect impact of external factors that affect the water quantity and quality as well as the social productive force.

through detailed socio-hydrological studies. These interactions can be compactly depicted by a Taiji wheel, as shown in Fig. 3a. The term Taiji is a special concept in Chinese philosophy, which means the evolution of a system as a result of interactions among the two opposite components (Yin and Yang poles). The two poles are contradictory but also depend on each other. Generally the Yang pole dominates the system evolution, but the Yin pole can be converted to the Yang pole under some specific conditions and vice versa. The outer environment could be composed of various natural factors (e.g., climate, underlying geology, ecological systems, etc.) and human factors (e.g., other SHSs, neighboring regions or states). The outer environment could itself be a Taiji-style system as well (e.g., a SHS operating at a larger scale), in other words, an evolutionary system driven by its own internal interactions, but this is beyond the scope of the study of a specific SHS such as the TRB. The change/evolution of the outer environment shall always interact with the inner Taiji SHS. Notionally, we can call the outer circle as the outer tire (see Fig. 3b), and for this reason the framework we have proposed is called the Taiji-Tire model.

The co-evolution of a specific SHS (as in the case of the TRB) is driven by the inner Taiji and the outer tire simultaneously. For the outer tire, environmental change, especially climate variability (and change) will directly impact the hydrological system within a specific SHS (e.g., water part in the inner Taiji), which will then impact the human part by way of interactions between water and humans. Therefore, climate variability/change can serve as an important external force for the evolution of a given SHS. For the inner Taiji, all the internal interactions between humans and water assume various forms via water consumption activities, which are dominated by human behavior and their personal and societal motivations. In some political-economic discourses (e.g., Marxism), a so-called social productive force is assumed to be the principal driver of societal evolution. All those forces which are employed by people in the production process (body \& brain, tools \& techniques, materials, resources and equipment) are encompassed by the concept of the social productive force, including those management and engineering functions technically indispensable for production. The social productive force is an integrated measure of tool, technology, societal organization, management, and so on, and serves as an important internal force driving the evolution of the SHS.

The co-evolution of the human-water system is therefore governed by both internal and external drivers. Considering the nature of the human-water relationship, including the interactions between water quantity and quality and human water consumption, the water condition can be considered stationary from a long-term perspective without regard to the evolution of the outer tire, with the key driver being the social productive force, which is determined by technology, social regimes, social scales, etc. For example, the growth of the social productive force has underpinned 200 years of agricultural development in the Mississippi River basin, which in the end has caused significant changes in water quality (Turner and Rabalais, 2003). The social productive force represents the abilities of humans to exploit natural resources. However, when it advances beyond some critical threshold value, it may drive the SHS into a new stage. External factors, divided into natural factors such as climate, weather, vegetation, soil, landforms and geological condition, and social factors such as culture, policies, wars, diseases, as shown in the outer tire in Fig. 3a, drive the co-evolution of the SHS by affecting water quantity and quality, and also by embracing the key role of the social productive force. According to our Taiji-Tire model, the natural variation and social productive force are the two key drivers for the development of any given SHS.

From the historic viewpoint, the social productive force is the key driver for human societal development. For example, the invention and application of iron tools enabled humans to cultivate larger land area than that during the Copper Age. The industrial revolution has enabled humans to use machines and the same goes for discoveries of electricity and the invention of computers. The upgrading of the social productive force determined the productive relationship and governed the formation of cultures, economy, politics and the human-environment relationship, including the human-water relationship. On the other hand, natural factors such as climate change and geographic/geological effects have long-dominated the fundamental landscape of the eco-hydrological environment and impacted the human societies populating it. The variability of natural factors such as hydrology and meteorology restricted the spatial extent of human activities and gradually formed specific regulation of behaviors and thoughts, which evolved into culture and values. 
Therefore, when social productive force is low and the human-water relationship is dominated by natural/physical factors, changes of the SHS usually coincide with hydrological or meteorological variations and social responses follow. We will discuss this in Sect. 4. With the upgrading of the social productive force, the SHS grew to become larger and social factors (represented by social productive force) became the main driver for the system shifts. Water consumption took on multiple forms and the human-water system became more complex. Positive interactions speeded up the evolution of the SHS and more problems also appeared. We will discuss this in Sect. 5. When water problems became more challenging, the human-water relationship became a new issue for not only scholars but for the whole society. Measures were taken to face the water problems and the human-water relationship evolved in response, which will be discussed in Sect. 6.

\section{Natural stage (up to the 18th century): natural factors dominate socio-hydrological change}

\subsection{Climate variation and river course change}

Historically, a remarkable feature of the Tarim River is that it experienced frequent and significant changes to its river courses. Recent remote sensing studies (Bai, 1994) show that the Tarim River system had two main courses (i.e., north Tarim River and south Tarim River) about 10000 years ago, and had preserved this two-course pattern until at least the 6th century AD, as shown in Fig. 4a and b. Also, historical literature such as the Book of Han (written by Ban Gu in AD 80) and Shui-Jing Zhu (literally "Commentary on the Waterways Classic", written by Li Daoyuan in the 6th century AD) documented that the ancient Silk Road had two routes (i.e., northern and southern) along rivers in the TRB, which implied that there existed two main rivers during the 5-6th centuries AD. The two books also say that the vegetation cover along the two main streams of the Tarim River was lush and also that there existed many oases. However, the Tarim River system has dramatically changed since then and by the 19th century it had finally evolved into a four-sourceone-mainstream pattern that exists presently (see Fig. $4 \mathrm{c}$ and Sect. 5.1 for more detail). By comparing the historical patterns of the Tarim River system shown in Fig. 4a-c, an obvious change can be detected in the south Tarim River, which gradually broke up into several smaller isolated river systems with the southern mainstream completely disappearing. Also, the northern mainstream has shrunk significantly and it no longer flows into Lop Nor Lake as it did before.

Another major feature of the Tarim River basin is that its climate experienced several back and forth swings between cool-dry and warm-wet regimes over the past 2000 years (as shown in Fig. 5), which are closely linked to the migration of the river courses. The earliest written history of the TRB

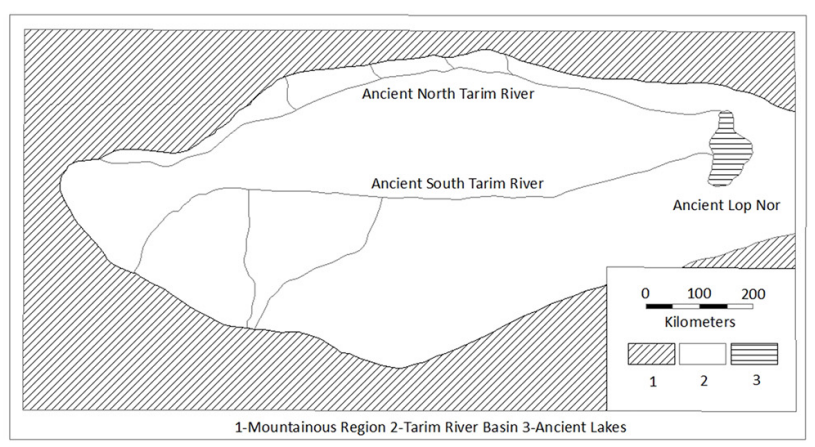

(a)

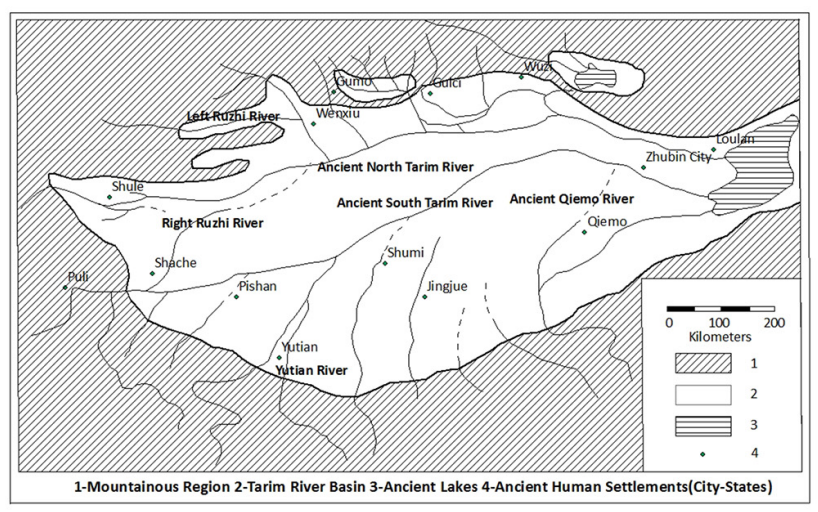

(b)

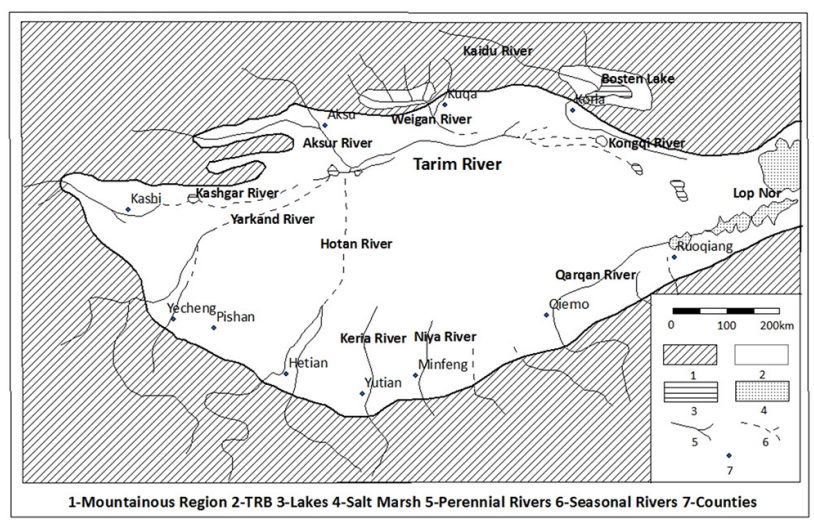

(c)

Fig. 4. Evolution of Tarim River system during the past tens of thousands of years: (a) TRB in the late Pleistocene (about 10000 years ago); (b) TRB from the 4th to 5th centuries; (c) TRB today (adapted from Fan, 1991; Bai, 1994).

began from Zhang Qian's voyage to the West Regions during the Han Dynasty (i.e., 137 BC), during which the climate of the TRB was characterized by warm and moist conditions (Sun et al., 2005). The plentiful precipitation and meltwater from Mt. Tianshan and Mt. Kunlun supported a much larger river system than exists today, and the large volumes 
of water flowing from the North and south Tarim rivers into Lop Nor supported a vast lake surface with abundant vegetation around it. Afterward, however, from the 3rd to 7th centuries $\mathrm{AD}$, the climate of TRB underwent a fluctuating down-trending of both precipitation and temperature (Sun et al., 2005; Han, 2010). Consequently, less water discharged into the main streams of Tarim River and Lop Nor, and more sediment deposited in the river bed, thus helping to intensify fluvial processes. The changed hydrological situation led to more frequent migrations of river courses, and several branches such as the Niya River began to disconnect from the Southern Tarim River system. Meanwhile, the Kongqi River (a source river of the north Tarim River, see Fig. 2) lost its connection with the main stream of north Tarim River which moved southward, resulting in a much reduced discharge into Lop Nor (Hu, 1990). In the book of Buddhist Records of the Western World written by Monk Xuanzang in the 7th century during the Tang Dynasty, he describes a degraded picture of the Tarim River, with drying lower reaches, withered vegetation, expanding desert, and abandoned farmlands and settlements; this record clearly shows the consequences of the cool-dry climate when compared to the picture described by Zhang Qian and later in Shui-Jing Zhu.

After the 7th century AD the climate of TRB returned back to the warm-moist pattern, which lasted for about 300 years until the 10th century AD (Shu et al., 2003; Sun et al., 2005). During this transition period, floods occurred frequently, which again caused migration of the river courses. However, after the 10th century AD, the fluctuating cooldry trend dominated climate variability again for another 500 years, and then a little ice age began from around the 15 th century, which reached its peak in the 17th century, and continued for another 100 years afterward (Sun et al., 2005). During this period of about 800 years, the dominant feature in the Tarim River was the shrinking of main streams and branches, together with the expansion of the desert, the out-migration of humans, and abandonment of human settlements. The south Tarim River system, as recorded, returned to the disconnected pattern that existed during the 3rd to 7th centuries (i.e., cool-dry period). The whole river system finally broke up into several parts and gradually evolved into several smaller separated river systems during the 19th century (as shown in Fig. 4c). Simultaneously, the main stream of north Tarim River moved gradually southward to the route along which the present Tarim River is now flowing.

\subsection{Human history and the abandonment of settlements}

When we carefully examine China's history before the 19th century, it can be seen that the total human population grew slowly but with periodic fluctuations caused by social shocks such as wars (Durand, 1960). In a similar way, the population of TRB did not increase significantly before the late 18th century. Human population numbers grew from 230000 in the 2 nd century $\mathrm{AD}$ (the total population of 36 city-states in West
Regions as recorded in the Book of Han), to reach 300000 in 1760 when the Qing Dynasty recontrolled Xinjiang (Hua, 1998; Shu et al., 2003; Lu and Fan, 2009). Also during this long period, the technology level was low and social organization was weak. Therefore, human society possessed a low level of productive force and limited influence on the environment, including the natural hydrological system.

A far-reaching event that occurred during the early development stage of the TRB was the opening up of the famous Silk Road in 138 BC by Zhang Qian, who was the imperial envoy of the Han Dynasty to the West Regions. West Regions (or Xiyu) was a historical name in Chinese chronicles between the 3rd century BC to the 8th century $\mathrm{AD}$ and referred most often to Central Asia but sometimes specifically to the TRB (the easternmost region of Central Asia) (see Wikipedia website, http://en.wikipedia.org/wiki/ Western_Regions). The Silk Road connected East Asia with the Indian sub-continent, Central Asia, Asia Minor and Europe, and made the TRB the meeting point between various ancient civilizations. After Zhang Qian, the West Regions began to be governed by China and to be recorded in Chinese literature as well, which enables us to access the plentiful historical material and data and examine the humanenvironment relationship in the ancient TRB.

The ancient human society in the TRB as a whole did not form a unified country and for a long period existed as isolated city-states. As recorded in the Book of Han, all the 36 city-states of the West Regions, located within the TRB around 2000 years ago, had small populations ranging from mere hundreds to thousands each. After the opening-up of the Silk Road, the Han Dynasty set up the Authority of West Regions to govern both the West Regions and the business route to the western world. Afterward, the city-states within TRB developed quickly through communication with both the eastern and western worlds for advanced agricultural and commercial technologies and ideas and thoughts. Also, the Silk Road turned the West Regions into a much more diverse area, with multiple races and multiple cultures (Yin, 1989), which shaped civilization and the social organization that formed as a result. The mixing of agriculture (farming), fishing, grazing and commerce made the TRB human society more stable than the nomadic society in the north or the commercial society in the west, but also more mobile than the traditional agricultural societies in the east. As a result, the city-states within the TRB became sensitive to social and environmental stresses and were apt to migrate compared to traditional agricultural societies.

The lower level of productive force and the higher mobility of society were the most important internal reasons for the abandonment of settlements in history, while the climate variations and the hydrological responses to these variations (which ultimately caused a shift of the river courses) functioned as external direct drivers, in addition to some social factors that operated at much larger scales. The prosperous period after the Silk Road lasted 300-400 years, mainly 


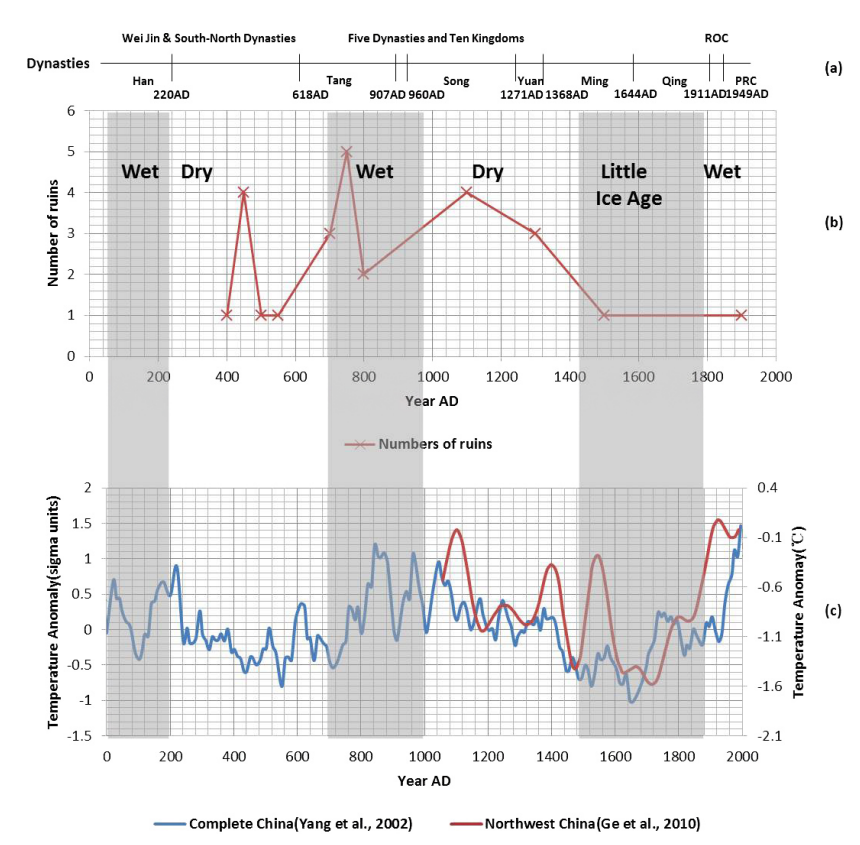

Fig. 5. Climate change and abandonment of human settlements during the past 2000 years within the Tarim River basin: (a) main imperial dynasties in China's history; (b) number of ruins, indicating the abandonment of human settlements; (c) temperature variation. Note that the whole period was divided into wet and dry sub-periods according to the reconstructed record of precipitation (Yang et al., 2002; Ge et al., 2010), of which the wet period is illustrated in grey.

during the Han Dynasty, but was interrupted by hundreds of years of cool-dry climate and the resultant river course migrations. Many well-known ancient human settlements were abandoned during this period (see the first peak in Fig. 5b), such as the famous Lolan, Keriya and Niya ruin groups. These states and villages started to decline from the 3rd to 4th centuries $\mathrm{AD}$ and finally collapsed around the 7th century AD (Shen et al., 1982; Wang, 1998; Zu et al., 2001). One can note that this timeline is coincident with the cooldry tendency of climate shown in Fig. 5 (Wang, 1998; Yang et al., 2006).

Another fast growth period of the TRB was during the Tang Dynasty (AD 618-907). The powerful Tang Dynasty effectively repossessed the West Regions from the mid-7th to early 9th centuries by setting up an administrative agency along with a resident army. A 100 year-long peaceful period that arose helped to recover social production, contributing to prosperity of agriculture, business, and population. The rule of the Tang Dynasty in the TRB, however, was seriously challenged by Arab states in the late 8th century and the Great Battle of Talas between the army of the Tang Dynasty and Arab forces took place in AD 751. The expeditionary army of the Tang Dynasty stationed in the West Regions and their allies were defeated in Talas (presently in current Kazakhstan) and the Tang Dynasty lost its influence over the West Regions. The wars between these eastern and western em-

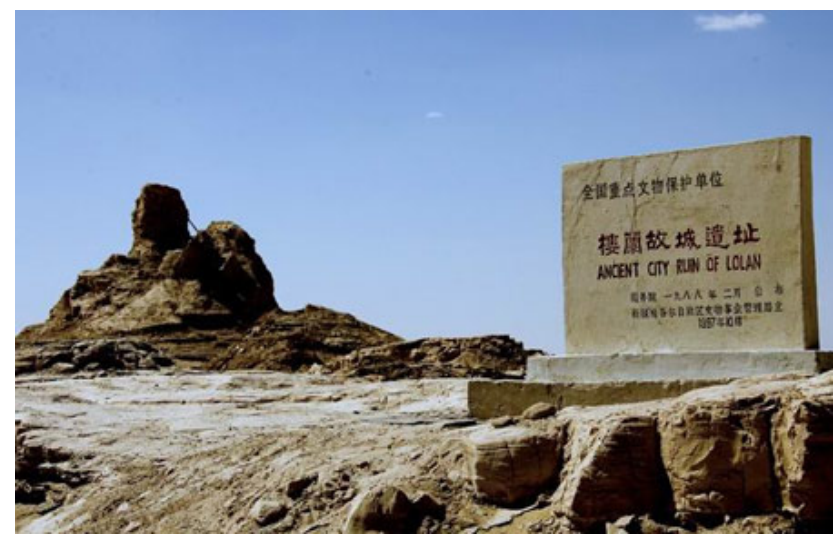

Fig. 6. Ruins of Lolan, which was abandoned around the 6th century AD (adapted from http://info.hotel.hc360.com/2010/06/ 091417209847-2.shtml).

pires interrupted the normal development of the TRB socioeconomy. As a result, many human settlements were abandoned during the strained years during the mid-8th century despite the beneficial climate (warming and wet, as shown in Fig. 5c). It is worth noting that ruins of these abandoned settlements were not found until the 10th century AD when the warm-wet climate changed its pattern again (Shu et al., 2007).

After the 10th century, there were two other episodes of abandonment of settlements, according to recent archeological research (Shu et al., 2007). One happened around the 11th century and another around the 13th century (see Fig. 5b), when the climate was in the cool-dry regime. Also, during that time the TRB was controlled by non-agricultural powers such as the Arabs, Huihus and Mongols. The agricultural fields were changed back to grazing, which reduced the capacity for food production. In fact, a similar phenomenon happened several times before as well. For instance, as early as in the 4th century AD (i.e., during the Eastern Jin Dynasty), the lower Tarim River basin was once controlled by Tubo (an ancient name for Tibet in Chinese history), when irrigated agriculture along the south edge of TRB partially retrogressed to grazing or an even more primitive socioeconomic formation. With the development in reverse, the size of the SHS was reduced, accompanied by a decreased human population and also a reduction of system complexity (Han, 2010).

\subsection{Natural dominated socio-hydrological system}

During the 2000 year long history until the 18th century, the societies that developed within the TRB were basically restricted to living within oases, which were isolated from each other. Due to the absence of mutual connection of both economy and politics, each isolated city-state could be regarded as separate SHSs, and the TRB before the 19th century could be considered as a set of isolated small SHSs. In 
the ancient agricultural oasis states within the TRB, farmlands were owned by farmers, and a primitive cultivation method called Chuangtian was practiced. With this method, the land was leveled in August and then a hole was dug on the river bank for flood irrigation. Seeds were sown in the next spring and from that time forward the farmers had nothing to do until harvest time in July. Abandonment and disuse of the land were very common, and the fallow period could last between 4 and 5, even up to 10 years (Han, 2010). Owing to the technological limitation, diversion canals could not be dug too far from the river bank and cultivation was constrained to the riparian area. This way of cultivation and irrigation was quite sensitive to climate fluctuations and river channel changes, which therefore led to high vulnerability of society to natural climate variability and hydrological change. When the river course migrated substantially or when the tail section of main river shrank upstream of a settlement, societies had no capability to adapt to the changed situation and primitive agriculture would thus collapse and settlements would be abandoned (remember Fig. $5 \mathrm{~b}$ and our discussion on the ruins in Sect. 5.2). Essentially, as per the Taiji-Tire model, water was consumed for primitive traditional agriculture and associated extensions. The human-water relationship was simple, without any kind of sophisticated irrigation practice or water management regime. There was a serious lack of water conservation policies and associated cultural and other social elements.

Therefore, given the lower level of social productive force, not surprisingly, the evolution of Tarim SHS was dominated by natural factors such as climate variability and river course change. For example, the smaller separated river systems of ancient south Tarim River reached far into the desert to its current location, implying that the desert was smaller than it is today. The evidence also comes from archeological research, which showed that the ruins belonging to the 10th century $\mathrm{AD}$ and before are mostly located tens to several hundred kilometers into the present desert, while those after the 10th century AD are found several to tens of kilometers into the desert, and the direct reason for their abandonment was river channel shifts and zero-flow conditions $(\mathrm{Zu}$ et al., 2001). Another peak of settlement abandonment occurred in the 8th century AD when the climate had just turned into warm and wet. As discussed in the previous section, this abandonment was partly caused by social shocks, including the Battle of Talas and a period of social unrest. However, this is a transitional period from the cool-dry to the warmwet regimes, and natural factors could also partly explain the abandonment, as the sharp change of climate broke the equilibrium of the SHS during the long cool-dry period (about 500 years, as shown in Fig. 5b). For example, a long period of dry conditions could result in the shrinking of the river channel section and consequently low flood-carrying capacity. When climate became wet, more water may have discharged into the previously shrunk river, leading to frequent floods and causing disastrous consequences for the TRB so- ciety. The human-water systems within the SHS were broken up due to natural disasters and consequently the SHS disintegrated. Once the eco-hydrological system became stable again, humans would find a suitable site to settle down again and develop a new SHS. When the connections between human and water systems were rebuilt in this way, the newly reformed SHS system would gradually evolve into a new equilibrium state. As a consequence of the adaptation of the new SHS with the new environment, fewer settlements were abandoned since the 9th century AD, as shown in Fig. 5b.

However, at local scales, social factors could also play a significant role in the evolution of SHSs during some specific periods. The social structure of city-states within the TRB presented a new city-centered pattern of agricultural activities (Wei, 2008), perhaps owing to the attraction of cities in the economy, and the flow of the Tarim River was undoubtedly reduced as more water was diverted for irrigation, which aggravated downstream water shortage and contributed to the shrinkage of lower river reaches. More importantly, due to the interactions between the Tire and the Taiji, the rise and fall of eastern agricultural dynasties had a great impact on local social factors, such as the size of the human population and water policies, and therefore influenced the SHSs within TRB. An interesting phenomenon was that when the West Regions were effectively managed by strong eastern agricultural dynasties such as the Han and the Tang, the farmland and population increased significantly as society developed a higher level of social productive force. During the Han and Tang dynasties, the reclamation of arable land by the army from middle China improved agricultural techniques through the introduction of advanced tools and expertise (Liao, 2011). More water infrastructures such as irrigation canals were constructed, which played an important role in farmland growth from the riverside into the desert and led to increasing water consumption (Wei, 2008).

\section{Exploitation stage (from 18th century to mid-20th century): increasing impact of humans}

\subsection{Change of river systems}

During the 18th century, the mainstream of the south Tarim River gradually disappeared, which left several smaller separated river systems in the southern edge of TRB. For the north Tarim River, the downstream channel shifted frequently, which led to a southward movement, together with its terminal lakes (i.e., Lop Nor) (Han, 2010). According to historical record in the books of He-Yuan-Ji-Lue (written by Ji Yun in the mid-18th century) and the Record of Rivers in the West Regions (written by Xu Song in 1821), the Tarim River system presented a 7-source-1-mainstream pattern, of which the mainstream was the north Tarim River. At the end of the Little Ice Age in the late 19th century and early 20th century, the climate changed back again to warm-wet 
pattern, which resulted in increased flow in the mainstream and source rivers, such as the Weigan River in the middle Tarim Basin. The increased discharge expanded the main channel of the Tarim River into two courses within the Luntai County, but it merged back into one again when it flowed out of Luntai, whereas Lop Nor Lake expanded its surface area to hundreds of square kilometers, with an abundant coverage of Euphrates Poplars and Tamarisks. Restoration of natural vegetation was limited, however, by increased water extraction within the source and upstream areas of the Tarim River due to the extension of farmland. From the 1910s to 1940s, at least eight major channel shifts occurred within the lower Tarim River and caused the degradation of the local and regional eco-hydrological system (Han, 2010, 2012). In the mid-20th century, several source rivers gradually lost contact with the mainstream of the Tarim River, including Weigan River in the middle part of the basin and Kashigar River in the upper part. Only four main source rivers were left, namely the rivers of Aksu, Yarkand, Hoton and KaiduKongqi, as shown in Fig. 4c.

\subsection{Expansion of traditional agriculture until mid-20th century}

In the TRB traditional agricultural society lasted for a long period until the mid-20th century. Generally, the utilization level of water resources was low, and especially before the 18 th century, the development of the socio-economy was rather sluggish. However, since the 18th century, the TRB society has experienced fast growth due to reforms of technology, social organization and management, which can be divided into two sub-periods (Table 1).

The first sub-period was from the 18th century to late 19th century. During the 1760s the Qing Dynasty brought together the nomadic civilizations and overcame the influence of Tsarist Russia. A reclamation and settlement policy was adopted to supply the army stationed in the region. There were four different kinds of stations for reclamation and settlement; these included a soldier station run by the resident army, a household station run by farmers who had migrated from central China, a Hui station operated by idle people of the Eight Banners (a military organization in Qing Dynasty), and a transfer station operated by criminals and political prisoners exiled from central China (Fang et al., 2007). Another important policy reform was Tan-Ding-Ru-Mu in the late 18th century, which linked taxation with the area of farmland instead of number of people. The previous censusbased tax system was called head tax or poll tax, which had been used for thousands of years in China. With this tax reform the enthusiasm of farmers was aroused and both agricultural production and government revenue increased significantly, which in turn promoted agriculture development by more reclamation and canal construction (Wang, 1971). Other than the profound influence of the tax reforms, innovative farming and engineering methods were introduced such as better seeds, new crops, and the Qanat irrigation system. Social reform and the advancement of technology led to the expansion of farmland and increased agricultural yield, which reached the average per unit yield of central China at the end of Qing Dynasty (Lu and Fan, 2009). According to Records and Maps of Xinjiang (written by Wang Shu'nan in early 20th century, with further additions in subsequent decades), irrigated land in TRB was over 11 million mu in early 20th century (mu is an area unit in China, $1 \mathrm{mu}$ equals $1 / 15$ of a hectare, and so 11 million mu is about $7500 \mathrm{~km}^{2}$ ), most of which was newly reclaimed during Qing Dynasty and located mainly in source river basins and the upper Tarim River area.

The second sub-period was from the late 19th century to the mid-20th century, during which China had experienced 100 years of unrest. The invasion from western powers (i.e., Opium war in 1840, Second Opium War in 1860, EightNation Allied Forces invasion in 1900, First Sino-Japanese War in 1904-1905, Second Sino-Japanese War, which was also called Anti-Japanese War, in 1937-1945) and civil wars (i.e., the Taiping Heavenly Kingdom War in 1851-1864, the Revolution of 1911 that overthrew the Qing monarchy, wars between warlords, two Kuomingtang-Communist Wars before and after the Anti-Japanese War in 1927-1936 and 1946-1949, respectively), along with natural disasters and social problems, such as diseases, interrupted the normal development of TRB society. The expansion of farmland ceased and some farmland retrogressed back to natural landscapes of grassland. For instance, the irrigated land in Hotan areas (an important agricultural county in south TRB) decreased while the population continued to grow, as shown in Fig. 7. The floating population, including migrants, refugees and idle persons, occupied over half the total population in agricultural counties like Hotan and Pishan (a nearby county), and became a serious hidden threat to social stability (Xie, 2008). In order to settle down the floating population and support the civil wars and the anti-Japanese War, the Government of the Republic of China then launched a reclamation campaign from the 1930s to the 1940s, which was historically unprecedented and highly influential. As a result farmland area once again increased, and similar to the Qing Dynasty, most reclamation concentrated in source river basins and the upper Tarim River area (Xie, 2008). The main difference between this sub-period of development and that of the Qing Dynasty was that this increase of farmland was driven purposefully by the government at a broader-scale, which is a stimulated response to a social problem, while the exploitation of farmland during the Qing Dynasty was a gradual procedure of coordinated social development.

A remarkable feature of the SHS during this period was that the ancient separated SHSs at the oasis scale were combined and evolved into a complex and intertwined system at sub-basin scale. With progress of politics, economy and culture, the different societies within the TRB melted into the Chinese nation gradually. Also, with the expansion of 


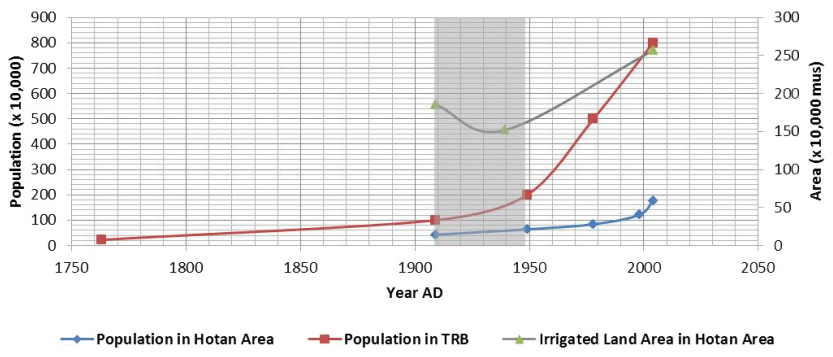

Fig. 7. Dynamics of human population and farmland area in Hotan region and over the whole Tarim River basin.

agriculture, more water was diverted for irrigation and the activities of upstream society obviously influenced the downstream.

\subsection{Impact of industrial technology since the mid-20th century}

Since the 1950s, especially after the establishment of the People's Republic of China, industrial technologies were introduced into the TRB and traditional agriculture was upgraded to modern (i.e., industrialized) agriculture, and industrial cities appeared. With the aid of modern technologies, large-scale irrigation infrastructures were constructed and farmland area dramatically expanded (Jiang et al., 2005; Han, 2012). As shown in Fig. 7, irrigated farmland and population in this period have grown at a much faster rate than ever before. Two new reclamation areas operated by the Xinjiang Construction Corps were developed, respectively, in the Aral area by the 1st Division (Aral City since 2002) and the Korla area by the 2nd Division. Supported by large, newly constructed diversion canals, the total farmland area of TRB reached 16 million mu (approximately $10000 \mathrm{~km}^{2}$ ) in 1999 according to the Statistical Yearbook of Xinjiang (1999 version).

Also, agricultural production has dramatically increased due to implementation of new farming methods, seeds, modern machines and techniques. According to the Statistics Yearbook of Xinjiang (1999 version), crop production per $\mathrm{mu}$ in the late 20th century had reached 150 to $200 \mathrm{~kg}$, which was much higher than the 50 to $75 \mathrm{~kg}$ that existed at the end of the Qing Dynasty (i.e., 1900s) (Lu and Fan, 2009). The expansion of agriculture elevated irrigation requirements dramatically. Since the 1950s, the increased water consumption has led to the disconnection of rivers of Kashigar, Weigan and Kaidu-Kongqi from the mainstream of the Tarim River. Groundwater table depth in the lower reaches was 3-5 $\mathrm{m}$ in the 1950s but dropped to $7-10 \mathrm{~m}$ in 1982 and to $11 \mathrm{~m}$ in 1986 , and in the middle reaches it dropped from $0.5-0.6 \mathrm{~m}$ in the 1950s to more than $2 \mathrm{~m}$ in 2004 (Feng et al., 2005).

Industrial products, such as fertilizers and pesticides, began to be applied in agriculture starting from the 1950s, which began to cause serious water quality problems. Vast quantities of sulfate, sodium, calcium, nitrogen and phosphorus had been applied to the soil in the form of fertilizers and these have leached into groundwater, resulting in higher salinity and other forms of contamination in rivers and lakes. The comprehensive pollution index of water quality at the Aral section in the upper Tarim River was 12.544 in 1998, indicating that the water was seriously polluted ( $\mathrm{Li}$ et al., 2006). Also, irrigation-induced groundwater table rise led to secondary salinization, which happened frequently in the source and upper Tarim areas, especially during the dry season (Wang et al., 2010).

In addition, the construction of reservoirs changed the hydrological and eco-environmental systems considerably. According to the Statistics Yearbook of Xinjiang (2012 version), by 2012 there were 125 reservoirs within the TRB. They are important for society since they provide water for agriculture, industry, and household use, and also reduce flood risk. At the same time, the reservoirs changed the pattern of river systems, leading to serious ecological and environmental problems. For instance, construction and operation of Daxihaizi Reservoir in the 1970s cut off the discharge to the downstream river and a $321 \mathrm{~km}$ stretch of river dried up quickly, contributing to a lowering of the groundwater level and the drying-up of the terminal lake. As a consequence, natural vegetation cover (mainly consisting Euphrates Poplars and Tamarisks forests) that used to separate Taklimakan Desert and Kumtagh Desert experienced massive die-off (Gao et al., 2007). According to the Taiji-Tire model, the application of industrial technology has enabled large-scale construction and profoundly changed the social regime and culture. The complicated outer tire leads to new water consumption patterns. The water consumption was no longer limited to the agricultural sector, which itself has evolved into more industrialized agriculture. Meanwhile, industry itself also consumes more water and changed the inner Taiji interactions by creating industrial cities and areas (discussed in Sect. 7.4). Consequently, the human-water relationship has further deepened.

\section{Environmental degradation and recovery stage (since mid-20 century): getting back to balance}

After two centuries of rapid development, the hydrological system within TRB has been substantially altered by humans. The over-exploitation of water resources has caused serious degradation of the natural ecological system together with significant invasion of desert. Since the 1990s, ecological disaster along the so-called green corridor of downstream Tarim River attracted considerable attention from researchers, journalists, the public and finally the government. In 1992, the Tarim River Basin Authority was set up in response to the integrated management of water resources within the TRB. Water diversion quotas were assigned for each district, and a series of water conservancy projects were implemented 


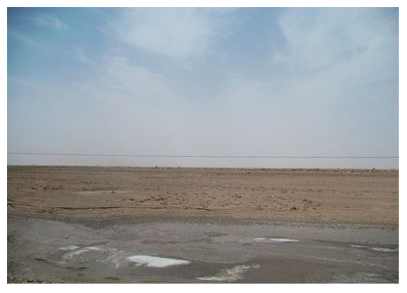

(a)

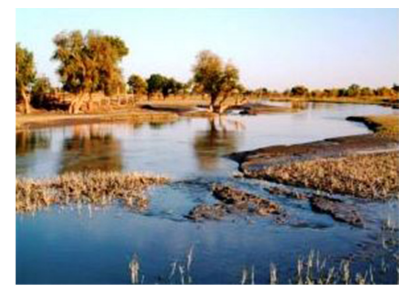

(b)

Fig. 8. Landscape around the Taitema Lake (a) around the 1970s when it was dry (adapted from http://pp.fengniao.com/photo_ 3809084.html); (b) and since 2000 after it had been refilled artificially through water transfers (adapted from http://a3.att.hudong. com/60/91/01300000633919130041912253732_s.jpg).

to save water from irrigation. Estimated total investment towards this restoration was 10.8 billion Yuan during the past 11 years (2001-2012).

The most direct measure to save the green corridor was emergency water transfers, which were implemented from Bosten Lake to terminal Taitema Lake for restoration of riparian vegetation. Since 1987, the TRB has been experiencing a warm-wet trend (Fan et al., 2011). The wetting signal is strong in the Kaidu-Kongqi River, which used to be a source river for the Tarim River but had lost hydraulic contact with the mainstream of the Tarim River during the natural stage. Then it rejoined the mainstream with human assistance and has been used for emergency water transfers from Bosten Lake to Taitema Lake. Emergency water transfers have been implemented a total of 13 times since 2000 and 4 billion $\mathrm{m}^{3}$ water was released from Daxihaizi reservoir to Taitema Lake (http://news.h2o-china.com/html/ 2012/11/110765_1.shtml). The seasonal flow reappeared in the downstream channel and the empty Taitema Lake was recharged to form a large water surface of over $200 \mathrm{~km}^{2}$ in the late 1990s. The groundwater table in the lower reach of the Tarim River rose from a depth of 6-8 $\mathrm{m}$ to a depth of 2-4 m, which enabled the regrowth of Euphrates Poplars, Tamarisks and reeds in the green corridor, covering an area of over $800 \mathrm{~km}^{2}$ (Deng, 2005; Chen et al., 2007b). Grass vegetation responded faster to the rising groundwater table than woody plants. The areas that used to be covered by Euphrates Poplars are less likely to be restored to their original vegetation but would be substituted by herbs or shrubs (Sun et al., 2004; Chen et al., 2006, 2007b). Nevertheless, the reappearance of the green corridor is essential for preventing the remerging of the Taklimakan desert with the Kumtagh desert (Gao et al., 2007). Besides, water quality has also been improved through fresh water recharge and shows a decreasing trend in the lateral direction, with a range of influence of 750 to $1000 \mathrm{~m}$ from the riverside, which basically spatially coincides with the area of groundwater table rise (Deng, 2005; Li et al., 2010).
However, the water transfer can be implemented only if it is pushed by the administrative power of the central government. Besides, it is just an emergency measure rather than a sustainable institutional measure. Also, the water conservancy projects were originally planned to save water from irrigated farmlands, to be released to the downstream for ecological recovery. However, in practice the saved water was intended to be used for newly reclaimed farmland, which means that the water was not actually saved for the ecosystem but used alternatively to stimulate even higher water demand (Zhang et al., 2014). Some scholars have called this phenomenon the efficiency paradox (Scott et al., 2013). The wish to provide water for natural vegetation was usually defeated by the impulse to make money through agriculture. A set of systematic measures including engineering, economic, administrative, and institutional aspects should be designed to provide the ecological water requirement in a sustainable manner. Regardless, society has finally begun the process of self-examination, which might lead to an effective course of self-regulation. The evolution of culture, social regime, technology and policy (important external social factors in the Taiji-Tire model) are now more environmentally friendly, which is definitely valuable for a sustainable management of the human-water system.

\section{Summary of historical socio-hydrology of TRB}

The historical analysis of co-evolution of the SHS within TRB has brought out distinct features of different socioeconomic formations, which are expressed in terms of system characteristics, human-water relationship, and the dominant driving forces. We have suggested that the coevolutionary changes that have occurred in the 2000-year history of the TRB can be summarized in terms of the Taiji-Tire model: a refinement of a special concept in Chinese philosophy relating to the co-evolution of a system because of interactions among system components. Based on the historical analysis of co-evolution of the SHSs within TRB, we found that 4 types of SHSs could be identified in terms of socioeconomic formation, i.e., primitive agricultural SHS, traditional agricultural SHS, industrialized agricultural SHS, and urbanized SHS. The spatial features and age differences between the 4 types of SHSs and the stages of co-evolutionary history of the SHSs within TRB are presented in Table 1.

\subsection{Primitive agricultural socio-hydrological system (before the 18th century in TRB)}

Before the advent of the agriculture industry, ancient peoples such as the Lopliks lived on fishing, hunting and gathering, which had a negligible impact on the natural ecosystem and also the water system. For the evolutionary study of SHS, we will ignore this social economic formation. The earliest example of a simple SHS is the primitive agricultural SHS that 
included low-level agricultural activities, simple tools and primitive social organization. The farmlands are linearly distributed along rivers and restricted within isolated areas (such as the oases within TRB primitive agricultural society). The societies relied principally on local water and land resources. No technologies or management tools had been developed to solve water shortage problems. Therefore, the size of primitive agricultural SHSs was constrained to be within a very small range. In the TRB, the existence of numerous abandoned settlements suggests the vulnerability of the primitive agricultural SHS due to small-scale and low social productive force (and thus low complexity of SHS). The primary driving force for the evolution of primitive agricultural SHS is the variability of natural factors, especially climatic and hydrological factors.

\subsection{Traditional agriculture socio-hydrological system (from the 18th to early 20th century in TRB)}

The highly developed traditional agriculture from the 18th century exhibited different features in terms of scale and coupled human-water relationships. Diversion canals began to be constructed but on a limited scale, which led to a transition of the spatial pattern of farmland from linear to planar distribution. The complexity of the SHS increased and its scale was enlarged, which was still limited by social factors such as institutional and technological advancement. Generally the evolution of traditional agricultural SHS is dominated by the variability of natural factors but human activities could dominate the SHS dynamics at the local scale.

\subsection{Industrialized agriculture socio-hydrological system (early to mid-20th century)}

The industrial revolution completely changed the intensity and extent of human productive activities. Also, it changed how people understand themselves and the natural environment. The social-organization of the SHS must be increasingly suitable for industrial production and accommodate modern societies with different urban and rural sectors. Large and complicated hydraulic projects and reservoirs have been constructed and the artificial water gradient has been greatly intensified. The comprehensive application of fertilizers and other modern tools have raised agricultural production remarkably and have caused severe soil salinization and water pollution. As a result societies have become totally dominant in the human-water relationship of industrialized agricultural SHSs.

\subsection{Urban socio-hydrological system (since mid-20th century in TRB)}

In a modern industrialized society, population and wealth are concentrated in the cities. Since the 1950s, modern cities like Aksu, Kashi and Korla have gradually emerged, in which the urbanization rate reached over $50 \%$ in 2005 ( $\mathrm{Li}$ et al.,
2010). The landscapes in urban and rural areas are totally different and the eco-hydrological and meteorological environments show distinct features. Modern cities are much larger and wealthier, with more functions, diverse landscapes and more complicated cultures, governance, economy and politics (Seto et al., 2010). They are not always located close to the riverside, as was the case with old cities. The interaction of human and water systems in urban areas is complex and co-evolutionary. On the one hand, the presence of a large population and industries demand a large quantity of water. This often leads to artificial water diversion from other river basin(s) to avoid over-exploitation of local water resources (surface water and groundwater). An example, located in California, USA, is the Central Valley Project and the State Water Project, both of which divert water from the northern Sacramento River and the San Joaquin River to large southern cities such as San Francisco and Los Angeles. Another example is the ongoing South North Water Transfer Project in China, which diverts a huge amount of water from the Yangtze River to large northern cities such as Beijing and Tianjin. In TRB, the scale of the SHS in urbanized societies is beyond the location of a river basin as long as the increasing demand for water leads to a connection between former isolated SHSs. On the other hand, with the rapid upgrading of the social productive force (technology, governance and social culture, etc.), more crops can be grown with less water, water markets and water trade have led to the flow of large quantities of virtual water and many societies can afford large-scale trans-basin water diversion projects. For instance within TRB, the efficiency of water consumption increased steadily from 1990 to 2005 coinciding with increasing total water consumption ( $\mathrm{Li}$ et al., 2010). All of these developments provide an opportunity to rebalance the humanwater relationship with changing spatio-temporal scales in a sustainable manner.

\section{Concluding remarks}

In this paper, based on the historical socio-hydrological method, we have analyzed the rich historical material available about human-water interactions within TRB, using the organizing framework offered by the Taiji-Tire model, which is a refinement of a special concept in Chinese philosophy, relating to the co-evolution of a system as a result of interactions among its components. This analysis has enabled us to recognize four main types of SHSs, and explain their historical evolution in terms of the concept of the social productive force. Nevertheless, this is still a site-specific study that reflects the historical experience in just one place. There is still a need to repeat this kind of study in several places in a comparative manner to confirm that the organizing framework and associated concepts also operate in other places. To be useful in practice, the conceptual model presented here must be transformed into a quantitative (numerical) model 
that can be used to explain the past and develop predictive insights about the future co-evolution of the coupled sociohydrologic system. This requires substantial new work that involves collection of historical data, creative analysis of the data and new data collection to test hypotheses about humanwater interactions and feedbacks, and develop the necessary constitutive relationships that characterize these. This is left for future research.

Acknowledgements. This research was funded by the National Science Foundation of China (NSFC 51179084, 51190092, 51222901), and the Foundation of the State Key Laboratory of Hydroscience and Engineering at Tsinghua University (2012-KY-03). This support is greatly appreciated.

Edited by: V. Srinivasan

\section{References}

Bai, Z.: Remote sensing study on the changes in Tarim River system, J. Cap. Norm. Univ. Nat. Sci., 15, 105-110, 1994.

Brink, A. B. A., Vanschalkwyk, A., Partridge, T. C., Midgley, D. C., Ball, J. M., and Geldenhuis, S. J. J.: The Changing Impact of Urbanization and Mining on the Geological Environment, S. Afr. J. Sci., 86, 434-440, 1990.

Chen, Y., Chen, Y., Liu, J., Li, W., Li, J., and Xu, C.: Dynamical variations in groundwater chemistry influenced by intermittent water delivery at the lower reaches of the Tarim River, J. Geogr. Sci., 15, 13-19, 2005.

Chen, Y., Li, W., Chen, Y., Zhao, R., and Wan, J.: Ecological response and ecological regeneration of transfusing stream water along the dried-up watercourse in the lower reaches of Tarim River, Xinjiang, Arid Zone Res., 23, 521-530, 2006.

Chen, Y., Li, W., Chen, Y., Liu, J., and He, B.: Ecological effect of synthesized governing in Tarim River valley, China Environ. Sci., 27, 24-28, 2007a.

Chen, Y., Li, W., Chen, Y., Xu, C., and Zhang, L.: Water conveyance in dried-up riverway and ecological restoration in the lower reaches of Tarim River, China. Acta Ecol. Sin., 27, 538545, 2007b.

Costanza, R., Graumlich, L., Steffen, W., Crumley, C., Dearing, J., Hibbard, K., Leemans, R., Redman, C., and Schimel, D.: Sustainability or Collapse: What Can We Learn from Integrating the History of Humans and the Rest of Nature?, Ambio, 36, 522527, 2007.

Deng, M.: Eco-environmental responses of the lower reaches of Tarim River to the emergency water deliveries, Adv. Water Sci., 16, 586-593, 2005.

Durand, J. D.: The population statistics of China, A.D. 2-1953, Pop. Stud., 13, 209-256, 1960.

Fan, Y., Chen, Y., Li, W., Wang, H., and Li, X.: Impacts of temperature and precipitation on runoff in the Tarim River during the past 50 years, J. Arid Land, 3, 220-230, 2011.

Fan, Z. and Cheng, X.: The geographical environmental change and agricultural development of Tarim Basin, Environ. Prot. Xinjiang, 1, 9-16, 1981.
Fang, X., Ye, Y., and Zeng, Z.: Extreme climate events, migration for cultivation and policies: A case study in the early Qing Dynasty of China, Sci. China Ser. D-Earth Sci., 50, 411-421, 2007.

Feng, Q., Liu, W., Si, J., Su, Y., Zhang, Y., Cang, Z., and Xi, H.: Environmental effects of water resource development and use in the Tarim River Basin of northwestern China, Environ. Geol., 48, 202-210, 2005.

Ferreira, S. and Ghimire, R.: Forest cover, socioeconomics, and reported flood frequency in developing countries, Water Resour. Res., 48, W08529, doi:10.1029/2011WR011701, 2012.

Gao, Q., Qu, J., Wang, R., Li, Y., Zu, R., and Zhang, K. C.: Impact of ecological water transport to green corridor on desertification reversion at lower reaches of Tarim River, J. Desert Res., 27, 52$58,2007$.

Ge, Q., Zheng, J., Hao, Z., Shao, X., Wang, W., and Luterbacher, J.: Temperature variation through 2000 years in China: An uncertainty analysis of reconstruction and regional difference, Geophys. Res. Lett., 37, L03703, doi:10.1029/2009GL041281, 2010.

Gordon, L. J., Peterson, G. D., and Bennett, E. M.: Agricultural modifications of hydrological flows create ecological surprises, Trends Ecol. Evol., 23, 211-219, 2008.

Han, C.: Studies on history evolution of human activity in the lower reaches of Tarim River under environment change, J. Glaciol. Geocryol., 32, 677-685, 2010.

Han, C.: Human activity, environment change and sustainable development pattern of Tarim mainstream in recent 250 years, J. Arid Land Resour. Environ., 26, 1-8, 2012.

Han, C. and Lu, G.: The changes of Lopliks living in the east of the Tarim Basin and their environment since the Qing dynasty, J. Chin. Hist. Geog., 21, 60-66, 2006.

Hao, X., Chen, Y., and Li, W.: Impact of anthropogenic activities on the hydrologic characters of the mainstream of the Tarim River in Xinjiang during the past 50 years, Environ. Geol., 57, 435-445, 2009.

Hu, W.: Xinjiang "Silk Road" and its environmental changes, Arid Zone Res.,4, 1-8, 1990.

Hua, L.: The agricultural development history of Xinjiang in Qing Dynasty. Heilongjiang Education Press, Harbin, 1998.

Ibe, K. M. and Njemanze, G. N.: The impact of urbanization and protection of water resources in Owerri and environs SE, Nigeria, Environ. Monit. Assess., 58, 337-348, 1999.

Jiang, L., Tong, Y., Zhao, Z., Li, T., and Liao, J.: Water resources, land exploitation and population dynamics in arid areas-The case of the Tarim River Basin in Xinjiang of China, Popul. Environ., 26, 471-503, 2005.

Klocking, B., Strobl, B., Knoblauch, S., Maier, U., Pfutzner, B., and Gericke, A.: Development and allocation of land-use scenarios in agriculture for hydrological impact studies, Phys. Chem. Earth, 28, 1311-1321, 2003.

Li, C., Yang, D., Zhang, Y., Qiao, X., and Liu, J.: Correlation between urbanization and water resources utilization in the Tarim River Basin, J. Desert Res., 30, 730-736, 2010.

Li, W., Hao, X., Chen, Y., Zhang, L., Ma, X., and Zhou, H.: Response of groundwater chemical characteristics to ecological water conveyance in the lower reaches of the Tarim River, Xinjiang, China, Hydrol. Process., 24, 187-195, 2010.

Li, X., Pan, X., He, B., and Wang, X.: Water quality assessment and ecological security research in main stream of the Tarim River, Arid Land Geogr., 29, 653-657, 2006. 
Li, Y., Li, Y., Zhou, Y., Shi, Y., and Zhu, X.: Investigation of a coupling model of coordination between urbanization and the environment, J. Environ. Manage., 98, 127-133, 2012.

Liao, Z.: The social designation regime and structure in ancient Western Region, Soc. Sci. Front, 109-113, 2011.

Lu, J. and Fan, Z.: The effects of the millitary reclamation on the agricultural development in Xinjiang during the Qing Dynasty, West. Reg. Res., 70-75, 137-138, 2009.

Pang, H., Chen, J., Pang, X., Liu, K., and Xiang, C.: Estimation of the hydrocarbon loss through major tectonic events in the Tazhong area, Tarim Basin, west China, Mar. Petrol. Geol., 38, 195-210, 2012.

Ponting, C.: A green history of the world: The environment and the collapse of great civilizations, St. Martin's Press, New York, 1992.

Schilling, K. E., Jha, M. K., Zhang, Y. K., Gassman, P. W., and Wolter, C. F.: Impact of land use and land cover change on the water balance of a large agricultural watershed: Historical effects and future directions, Water Resour. Res., 44, W00A09, doi:10.1029/2007WR006644, 2008.

Scott, C. A., Vicuña, S., Blanco-Gutiérrez, I., Meza, F., and VarelaOrtega, C.: Irrigation efficiency and water-policy implications for river-basin resilience, Hydrol. Earth Syst. Sci. Discuss., 10, 9943-9965, doi:10.5194/hessd-10-9943-2013, 2013.

Seto, K. C., Sanchez-Rodriguez, R., and Fragkias, M.: The New Geography of Contemporary Urbanization and the Environment, Annu. Rev. Env. Resour., 35, 167-194, 2010.

Shen, J., Gao, Q., and Hu, Z.: Preliminary study on desertification in southern area of Tarim Basin in the historical period, J. Desert Res., 2, 25-32, 1982.

Shu, Q., Zhong, W., and Xiong, H.: Study on the paleoclimatic ecolution and the vicissitude of human being's civilization in Tarim Basin since about 4.0k years, Hum. Geogr., 18, 87-91, 2003.

Shu, Q., Zhong, W., and Li, C.: Distribuion feature of ancient ruins in south edge of Tarim Basin and relationship with environmental changes and human activities, J. Arid Land Resour. Environ., 21, 95-100, 2007.

Sivapalan, M., Savenije, H. H. G., and Blöschl, G.: Sociohydrology: A new science of people and water, Hydrol. Process., 26, 1270-1276, 2012.

Sun, Q., Li, Z., Wu, S., Han, H., Xiao, C., and Liu, L.: The augment on the relations between the global environment changes and the evolution of the ancient oasis towns of Tarim Basin, J. Xinjiang Norm. Univ. Nat. Sci., 24, 113-116, 2005.

Sun, T., Li, J., and Du, L.: Remote sensing monitoring of ecological changes of lower Tarim River before and after the emergent water-transportation, J. China Inst. Wat. Resour. Hydropower Res., 2, 179-184, 2004.

Tong, Y.: Analysis on the population pressure based on the research on carrying pressure of water resources in different districts of Xinjiang, China Pop., Resour. Environ., 16, 78-82, 2006.
Tong, Y., Wu, C., and Wang, B.: The relations among population growth, water resources and desertification in Tarim Basin, Xinjiang. Pop. J., 37-40, 2006.

Turner, R. E. and Rabalais, N. N.: Linking Landscape and Water Quality in the Mississippi River Basin for 200 Years, BioScience, 53, 563-572, 2003.

Wang, B.: The excavation and study of ancient tomb in Kongqi River, Soc. Sci. Xinjiang, 117-128+130, 1983

Wang, G., Shen, Y., Zhang, J., Wang, S., and Mao, W.: The effects of human activities on oasis climate and hydrologic environment in the Aksu River Basin, Xinjiang, China, Environ. Earth Sci., 59, 1759-1769, 2010.

Wang, S.: The abandonment of three major ancient ruins groups and environmental change in Tarim Basin, Quaternary Sci., 18, 71-79, 1998.

Wang, Y.: The Fiscal Importance of the Land Tax During the Ch'ing Period, J. Asian Stud., 30, 829-842, 1971.

Wang, Z., Zhang, P., and Zhou, Q.: The impact of climate on the society of China during historical times, Acta Geogr. Sin., 51, 329-339, 1996.

Wei, X.: The historical feastures of water conservancy and irrigations in ancient Western Region in China, Agr. Archaeol., 34-37, 2008.

Xie, L.: The impact of agricultural development on ecological environment in southern edge of Tarim River Basin during the Qing dynasty and Republic of China period (i.e. 1644-1949), Shanghai People's Publishing House, Shanghai, 2008.

Yang, B., Braeuning, A., Johnson, K. R., and Yafeng, S.: General characteristics of temperature variation in China during the last two millennia, Geophys. Res. Lett., 29, 38-1-38-4, 2002.

Yang, X., Liu, Z., Mang, F., White, P. D., and Wang, X.: Hydrological changes and land degradation in the southern and eastern Tarim Basin, Xinjiang, China, Land Degrad. Dev., 17, 381-392, 2006.

Yin, Q.: The development of commerctial business and the activities of merchants in ancient Xinjiang, N. W. Ethno-National Stud., 138-153, 1989.

Zhang, Z., Hu, H., Tian, F., Yao, X., and Sivapalan, M.: Groundwater Dynamics under Water Saving Irrigation and Implications for Sustainable Water Management in an Oasis: Tarim River Basin of Western China, Hydrol. Earth Syst. Sci. Discuss., 11, 17771820, doi:10.5194/hessd-11-1777-2014, 2014.

Zhou, H., Zhang, X., Xu, H., Ling, H., and Yu, P.: Influences of climate change and human activities on Tarim River runoffs in China over the past half century, Environ. Earth Sci., 67, 231241, 2012.

Zu, R., Gao, Q., Qian, J., and Yang, J.: Environmental changes of oasis at the southern part of Tarim Basin during the recent 2000 years, J. Desert Res., 21, 122-128, 2001. 